\title{
Corrigendum: Effect of Perceived Negative Workplace Gossip on Employees' Behaviors
}

OPEN ACCESS

Approved by:

Frontiers in Psychology,

Frontiers Media SA, Switzerland

*Correspondence:

Ming Kong

kongming010@126.com

Specialty section:

This article was submitted to

Organizational Psychology,

a section of the journal

Frontiers in Psychology

Received: 16 December 2018

Accepted: 18 December 2018

Published: 11 January 2019

Citation:

Kong M (2019) Corrigendum: Effect of

Perceived Negative Workplace Gossip on Employees' Behaviors.

Front. Psychol. 9:2728.

doi: 10.3389/fpsyg.2018.02728
Ming Kong*

School of Management, Shandong University, Jinan, China

Keywords: perceived negative workplace gossip, in-role behavior, organizational citizenship behavior, organization-based self-esteem, perceived insider status, hostile attribution bias

\section{A Corrigendum on}

Effect of Perceived Negative Workplace Gossip on Employees' Behaviors by Kong, M. (2018). Front. Psychol. 9:1112. doi: 10.3389/fpsyg.2018.01112

In the original article, we neglected to include the funder "National Natural Science Foundation of China, 71872102." The updated funding statement is mentioned below:

This research was supported by National Natural Science Foundation of China (No. 71872102).

The authors apologize for this error and state that this does not change the scientific conclusions of the article in any way. The original article has been updated.

Copyright (c) 2019 Kong. This is an open-access article distributed under the terms of the Creative Commons Attribution License (CC BY). The use, distribution or reproduction in other forums is permitted, provided the original author(s) and the copyright owner(s) are credited and that the original publication in this journal is cited, in accordance with accepted academic practice. No use, distribution or reproduction is permitted which does not comply with these terms. 